\title{
Effect of Zn Application on Rhizosphere Acidification in Rice and Wheat Varieties of Varying Zn Sensitivity
}

\author{
Deepa Rawat ${ }^{*}$, Santosh Chandra Bhatt ${ }^{1}$, P.C. Srivastava ${ }^{2}$ and S.P. Pachauri ${ }^{3}$
}

Department of Soil Science, College of Agriculture, GB Pant University of Agriculture and Technology, District: Udham Singh Nagar, Uttarakhand- 263945, India

*Corresponding author

\section{A B S T R A C T}

Healthy seeds of different varieties of rice (PD 6, NDR 359, PD 16 and PS 5) and wheat (UP 262, UP 2628, PBW 175 and UP 2554) were germinated and fourteen days after germination, young rice/wheat seedlings were transferred to half strength of Hogland

\section{Keywords}

Zn Application, Rhizosphere, Rice and Wheat Varieties

Article Info

Accepted:

10 May 2019

Available Online:

10 June 2019 solution ( $\mathrm{pH}$ 7.0) containing either recommended levels of $\mathrm{Zn}\left(0.05 \mathrm{mg} \mathrm{Zn} \mathrm{L}^{-1}\right)$ or no $\mathrm{Zn}$ for four days. For solidification of medium $0.4 \% \mathrm{w} / \mathrm{v}$ agar- agar was mixed in the Hogland solutions of both $-\mathrm{Zn}$ and $+\mathrm{Zn}$. Prior to solidification, $11.25 \mathrm{~mL}$ of $0.1 \%$ bromothymol blue dye solution prepared in $60 \%$ ethanol and was mixed to agar nutrient solution. Twenty five $\mathrm{mL}$ of nutrient agar medium with $+\mathrm{Zn}$ or $-\mathrm{Zn}$ was poured in glass petri plates of $10 \mathrm{~cm}$ diameter and one seedling of each rice/wheat variety from $+\mathrm{Zn}$ or $-\mathrm{Zn}$ lot was transferred to the respective nutrient agar medium in duplicate. The colour change near roots under $+\mathrm{Zn}$ and $-\mathrm{Zn}$ were monitored and photographs were taken after $48 \mathrm{hrs}$ in case of rice and $72 \mathrm{hrs}$ in case of wheat for recording the extent of change in colour of the nutrient medium in the rhizosphere of all the rice and wheat varieties. In rice NDR 359 substantially reduced the $\mathrm{pH}$ in vicinity of roots (more yellow area around roots) than in $\mathrm{Zn}$ sufficient medium indicating possibly a better activity of the proton efflux pump to enhance $\mathrm{Zn}$ uptake under $\mathrm{Zn}$ deficient conditions. In $\mathrm{Zn}$ deficient conditions, $\mathrm{Zn}$ inefficient genotype UP 262 failed to substantially reduce $\mathrm{pH}$ in the vicinity of roots (less yellow areas around the roots) however, this variety under $\mathrm{Zn}$ sufficient conditions could reduce the $\mathrm{pH}$ of the growth medium (more yellowing around the roots).

\section{Introduction}

As an essential micronutrient, $\mathrm{Zn}$ is required for various physiological and metabolic processes in plants. It is the only metal which is present in the six classes of enzymes: oxidoreductases, transferases, hydrolases, lyases, isomerases and ligases (Auld, 2001). Plant response to $\mathrm{Zn}$ deficiency occurs in terms of decrease in membrane integrity, susceptibility to heat stress, decreased synthesis of carbohydrates, cytochromes, nucleotide, auxin and chlorophyll (Marschner, 1995). As $\mathrm{Zn}$ plays multiple roles in plant biochemical and physiological processes, even slight deficiency causes a decrease in growth, yield, and $\mathrm{Zn}$ content of edible plant parts. The ability of some crop genotypes to 
tolerate low $\mathrm{Zn}$ availability over others is still not fully understood (Hacisalihoglu and Kochian, 2003). However, it may be partially related to rhizosphere acidification via organic acid release as root induced chemical changes in the rhizosphere have been shown to influence the phytoavailability of soil $\mathrm{Zn}$ (Marschner, 1995). Cultivars within a plant species differ in their ability to take up Zn, which may be caused by differences in absorption, translocation and utilization of $\mathrm{Zn}$. Cakmak et al., (1994) showed that a Zninefficient durum wheat cultivar exhibited $\mathrm{Zn}$ deficiency symptoms earlier and more intensely than a Zn-efficient bread wheat cultivar even though the $\mathrm{Zn}$ tissue concentrations were similar in both lines, suggesting differential utilization of $\mathrm{Zn}$ in the two cultivars. Keeping in view the role of rhizospehere acidification in $\mathrm{Zn}$ uptake capacity of plant, the present investigation was performed to assess the mechanism of rhizosphere acidification in rice and wheat varieties of varying zinc sensitivity.

\section{Materials and Methods}

Healthy seeds of different varieties of rice (PD 6, NDR 359, PD 16 and PS 5) and wheat (UP 262, UP 2628, PBW 175 and UP 2554) varieties were surface sterilized using $0.01 \%$ solution of mercuric chloride. After thorough washing with distilled water, seeds were soaked in water and after 24 hours of soaking they were placed in loosely covered petri plates for germination and regularly watered with quartz distilled water. Fourteen days after germination, young rice/wheat seedlings were transferred to half strength of Hogland solution ( $\mathrm{pH}$ 7.0) containing either recommended levels of $\mathrm{Zn}\left(0.05 \mathrm{mg} \mathrm{Zn} \mathrm{L}^{-1}\right)$ or no $\mathrm{Zn}$ for four days. For solidification of medium $0.4 \% \mathrm{w} / \mathrm{v}$ agar- agar was mixed in the Hogland solutions of both $-\mathrm{Zn}$ and $+\mathrm{Zn}$ by gently heating till dissolution of agar and then removed from hot plate for cooling. Prior to solidification, $11.25 \mathrm{~mL}$ of $0.1 \%$ bromothymol blue dye solution prepared in $60 \%$ ethanol and was mixed to agar nutrient solution. Twenty five $\mathrm{mL}$ of nutrient agar medium with $+\mathrm{Zn}$ or $-\mathrm{Zn}$ was poured in glass petri plates of $10 \mathrm{~cm}$ diameter and one seedling of each rice/wheat variety from $+\mathrm{Zn}$ or $-\mathrm{Zn}$ lot was transferred to the respective nutrient agar medium in duplicate. The petri plates were gently tilted so that the roots were covered by the nutrient agar medium. The desiccation of the nutrient agar medium was checked by daily adding 1.5-2.0 mL distilled water to each petri plate. The colour change near roots under $+\mathrm{Zn}$ and $-\mathrm{Zn}$ were monitored and photographs were taken after $48 \mathrm{hrs}$ in case of rice and $72 \mathrm{hrs}$ in case of wheat for recording the extent of change in colour of the nutrient medium in the rhizosphere of all the rice and wheat varieties.

\section{Results and Discussion}

\section{Changes in rhizospheric acidity under $\mathbf{Z n}$ deficient and sufficient conditions in rice}

The data regarding the changes in rhizospheric $\mathrm{pH}$ of young seedlings of different rice genotypes raised in $\mathrm{Zn}$ deficient $(-Z n)$ or $Z n$-sufficient $(+Z n)$ solutions are given in Figure 1 and the plate 1 .

With the increase in soil $\mathrm{pH}, \mathrm{Zn}$ availability is reduced due to adsorption on the hydrous oxides of aluminium, iron and manganese or precipitation as specific compounds (Marschner, 1995). The root-mediated processes that could decrease the rhizosphere pH might be capable of increasing the plant $\mathrm{Zn}$ availability by solubilizing $\mathrm{Zn}$ from organic and inorganic soil solid phases. In lowland rice, rhizosphere acidification is likely to improve the utilization of $\mathrm{Zn}$ (Kirk and Bajita, 1995). Also, rice roots take up nitrogen mainly as $\mathrm{NH}^{4+}$, resulting in discharge of $\mathrm{H}^{+}$by roots which consequently 
decreases the rhizosphere $\mathrm{pH}$. In the present study, the solution $\mathrm{pH}$ which was initially 7 , ranged from 6.46 to 5.78 in $\mathrm{Zn}$ sufficient condition after 2 days of growth whereas, under deficiency of $\mathrm{Zn}$ the $\mathrm{pH}$ of the solution ranged from 6.64 to 4.76. As compared to the $\mathrm{Zn}$-sufficient medium the decrease in $\mathrm{pH}$ under $\mathrm{Zn}$ deficiency was more pronounced in NDR 359 than in PD 16 and PS 5. As shown in plate 1 , the photographs of roots of young seedlings of different rice genotypes raised on Zn-deficient or -sufficient agar medium mixed with $\mathrm{pH}$ sensitive dye indicated that under Zn deficiency NDR 359 substantially reduced the $\mathrm{pH}$ in vicinity of roots (more yellow area around roots) than in $\mathrm{Zn}$ sufficient medium indicating possibly a better activity of the proton efflux pump to enhance $\mathrm{Zn}$ uptake under $\mathrm{Zn}$ deficient conditions. According to Kirk and Bajita (1995), under anaerobic conditions $\mathrm{O}_{2}$ released from the roots lead to higher $\mathrm{H}^{+}$extrusion consequently increased $\mathrm{Zn}$ bioavailability for plants. Therefore, it was clear in the present investigation that NDR 359 was not able to take up sufficient $\mathrm{Zn}$ under deficient conditions and managed to take up $\mathrm{Zn}$ under deficient conditions by increasing the $\mathrm{H}^{+}$ efflux and releasing low molecular weight organic acids. Hajiboland et al., (2005) reported that citrate concentration in the fine roots with bicarbonate treatment ( $\mathrm{Zn}$ deficient condition) peaked at about $5 \mathrm{~mm}$ from the tip in the Zn-inefficient genotype (IR 26), whereas no peak was found in the $\mathrm{Zn}$-efficient genotype (IR 36). It is apparent from the photographs of PD 6 that as compared to $\mathrm{Zn}$ deficient condition more of the $\mathrm{pH}$ decrease (more yellow area around roots) around the rhizosphere took place under $\mathrm{Zn}$ sufficient medium but substantially lesser yellowness was observed in $\mathrm{Zn}$ deficient medium. This showed its lower tolerance and uptake capacity under $\mathrm{Zn}$ deficiency due to its lesser ability to reduce the rhizospheric $\mathrm{pH}$ when $\mathrm{Zn}$ was not present in sufficient amount in soil.
Hoffland et al., (2006) observed that under Zn deficiency, lowland rice increased citric acid exudation which resulted in reduction of rhizospheric $\mathrm{pH}$ to enhance $\mathrm{Zn}$ uptake and it was suggested that the citrate exudation capacity of rice genotypes was related to their tolerance to $\mathrm{Zn}$ deficiency. Even with sufficient amount of $\mathrm{Zn}$ present in the medium, PD 6 managed to take up $\mathrm{Zn}$ by reducing the rhizospheric $\mathrm{pH}$ and the proton efflux pump in this genotype had lower activity under Zn deficiency. In case of PS 5, no substantial difference in the colour around the root surface was observed in $\mathrm{Zn}$ deficient and sufficient medium whereas, in PD 16 the yellowness around the roots was more visible under $\mathrm{Zn}$ deficient plate than in $\mathrm{Zn}$ sufficient condition however, the extent was not as prominent as visible in $\mathrm{Zn}$ deficient roots of NDR 359.

Changes in rhizospheric acidity under Zndeficient and -sufficient conditions in wheat

The data regarding the changes in rhizospheric $\mathrm{pH}$ of young seedlings of different wheat genotypes raised in $\mathrm{Zn}$ deficient $(-Z n)$ or Zn-sufficient $(+Z n)$ solutions after four days are given in Figure 2 and the photographs are given in plate 2 .

The changes in rhizosphere $\mathrm{pH}$ occur as a result of excretion of protons $\left(\mathrm{H}^{+}\right)$and hydroxyl $\left(\mathrm{OH}^{-}\right)$or bicarbonate $\left(\mathrm{HCO}_{3}{ }^{-}\right)$ions due to a cation-anion imbalance in the plant, the evolution of $\mathrm{CO}_{2}$ by respiration, and the excretion of low-molecular-weight organic acids (LMWOAs) (Gao et al., 2012). The $\mathrm{pH}$ of medium initially 7 in which young seedlings of different wheat varieties were grown decreased after 4 days under both $\mathrm{Zn}$ deficient and sufficient conditions. The decrease in $\mathrm{pH}$ under $\mathrm{Zn}$ deficient medium was slightly more pronounced (ranging from 6.66 to 5.72) than in $\mathrm{Zn}$ sufficient condition (ranging from 6.71 to 5.80). Zinc deficient 
roots of two varieties i.e. Durati and Warigal, released correspondingly, five and three times more phytosiderophores and resulted a reduction in the rhizosphere $\mathrm{pH}$ than under $\mathrm{Zn}$ sufficient conditions (Rengel et al., 1998). However, in UP 262 the $\mathrm{pH}$ noted under $\mathrm{Zn}$ sufficient condition was slightly less than in $\mathrm{Zn}$ deficient medium. As shown in Plate 3, the photographs of roots of young seedlings of different wheat genotypes raised on $\mathrm{Zn}$ - deficient or -sufficient agar medium mixed with $\mathrm{pH}$-sensitive dye indicated that under $\mathrm{Zn}$ deficient conditions, $\mathrm{Zn}$ inefficient genotype UP 262 failed to substantially reduce $\mathrm{pH}$ in the vicinity of roots (less yellow areas around the roots) however, this variety under $\mathrm{Zn}$ sufficient conditions could reduce the $\mathrm{pH}$ of the growth medium (more yellowing around the roots).

Fig.1 Changes in rhizospheric $\mathrm{pH}$ in rice varieties in $\mathrm{Zn}$-sufficient and -deficient nutrient agar media

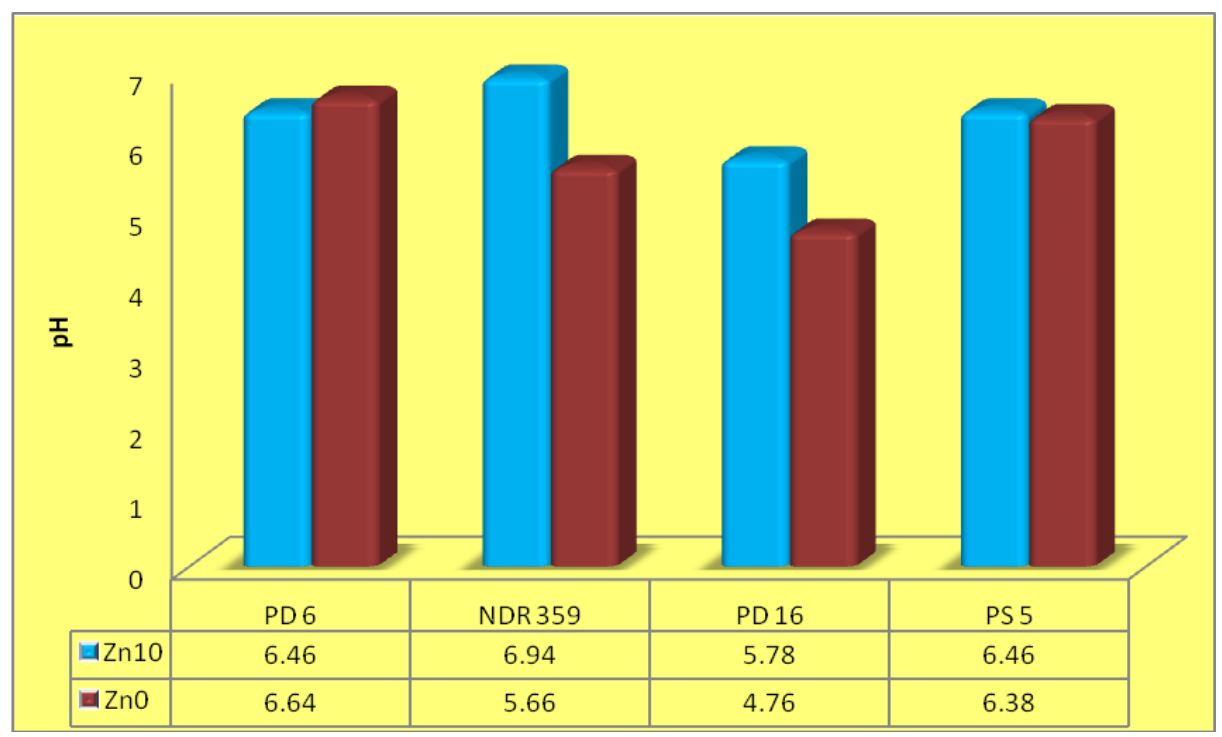

Fig.2 Changes in rhizospheric $\mathrm{pH}$ in wheat varieties under $\mathrm{Zn}$-deficient and sufficient conditions

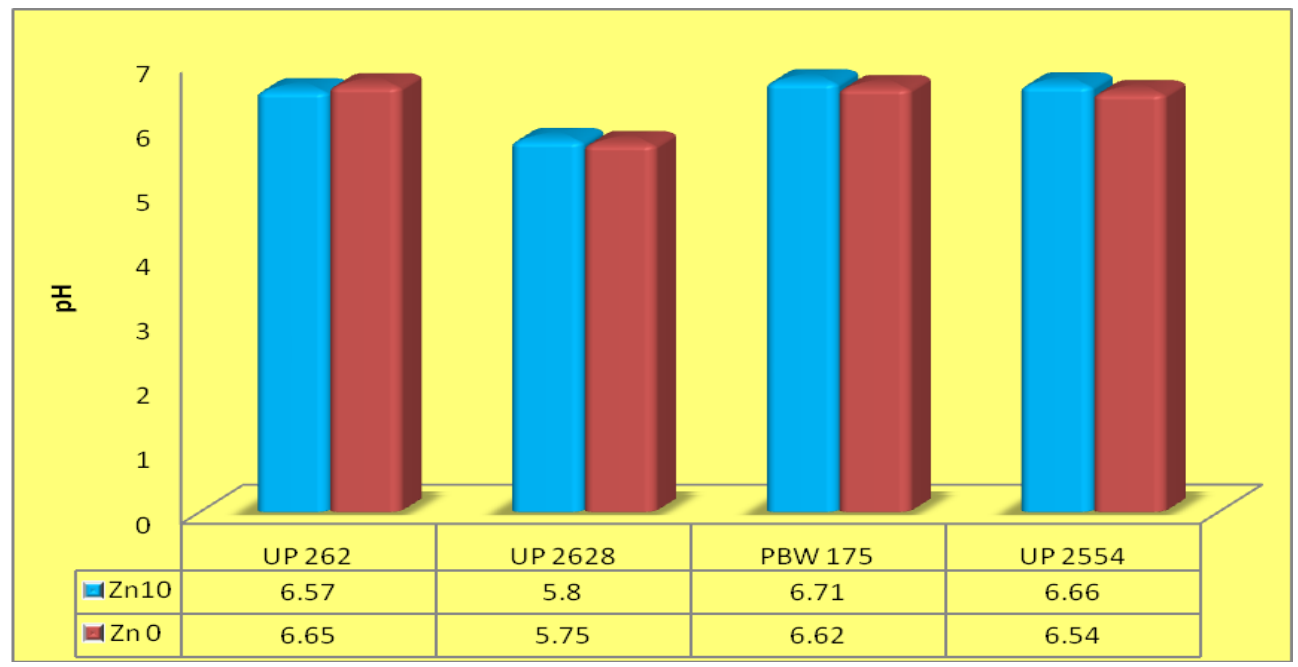



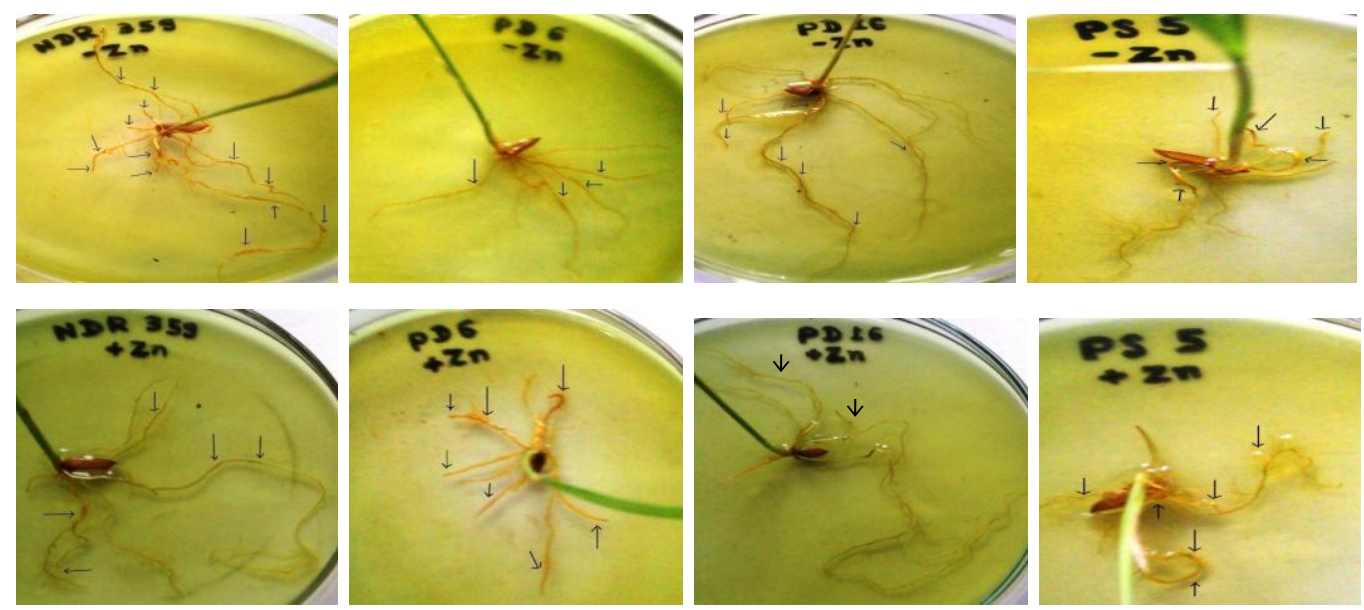

Plate 1: Changes in rhizospheric acidity under Zn deficient and sufficient conditions in rice
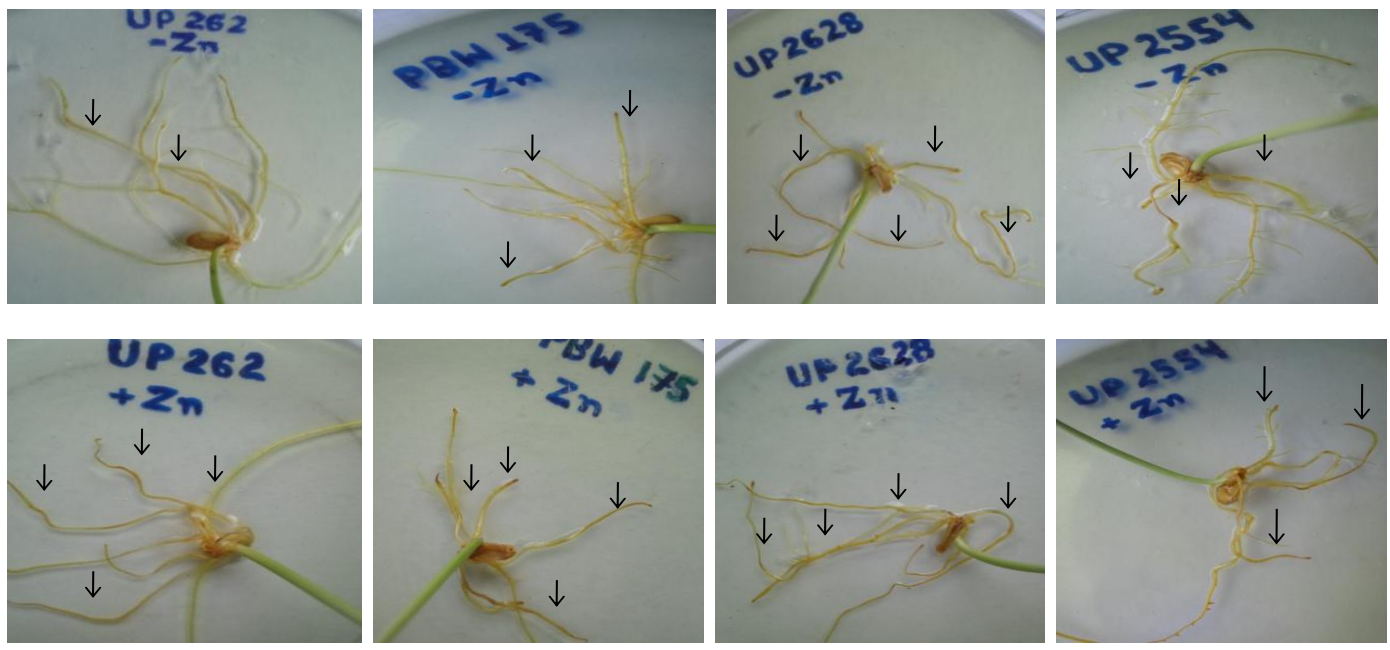

Plate 3: Changes in rhizospheric acidity under Zn deficient and sufficient conditions in wheat

This possibly indicated poor activity of proton efflux pump in this $\mathrm{Zn}$ inefficient genotypes under $\mathrm{Zn}$ deficiency. Under $\mathrm{Zn}$ deficient condition, an alternation of plasma membrane lipids had been reported to cause impairment in trans-plasma membrane proton gradient (Pinton et al., 1993). On the other hand, $\mathrm{Zn}$ efficient genotype (UP 2628) showed almost similar $\mathrm{pH}$ decrease in the growth medium under both Zn-deficient or sufficient condition and a similar extent of yellowing around the roots occurred under both $\mathrm{Zn}$ deficient and $\mathrm{Zn}$-sufficient conditions. Rengel (1999) compared the responses to $\mathrm{Zn}$ deficiency in two wheat genotypes (Triticum aestivum, cv. Aroona and T. turgidum L. conv. Durum, cv. Durati) grown in conventional and chelator-buffered nutrient solutions. With continuation of $\mathrm{Zn}$ deficiency stress, the Aroona plants grown in the conventional nutrient solution exuded increasing amounts of phytosiderophores into 
the medium thereby decreasing the $\mathrm{pH}$ in the root vicinity, while the plants grown in the Zn-deficient chelator-buffered nutrient solution generally could not sustain a high rate of phytosiderophore exudation at day 22 compared to younger plants. The variation in Zn uptake ability between bread and durum wheat cultivars was ascribed to differential release of phytosiderophores (Cakmak et al., 1996). The performance of genotypes PBW 157 and UP 2554 was intermediate between UP 262 and UP 2628.

\section{References}

Auld, D.S. 2001. Zinc coordination sphere in biochemical zinc sites. Biometals, 14: 271-313.

Cakmak, I., Sari, N., Marschner, H., Kalayci, M., Yilmaz, A., Eker, S. and Gulut, K.Y.1996. Dry matter production and distribution of zinc in bread and durum wheat genotypes differing in zinc efficiency. Plant Soil, 180:173-181.

Cakmak, S., Gulut, K.Y., Marschner, H. and Graham, R.D. 1994. Effect of zinc and iron deficiency on phytosiderophore release in wheat genotypes differing in zinc efficiency. J. of Plant Nutr., 17: 117.

Gao, X., Hoffland, E., Stomph, T., Grant, C.A., Zou, C. and Zhang, F. 2012. Improving zinc bioavailability in transition from flooded to aerobic rice. A review. Agronomy for Sustainable Development, 32(2):465-478.

Hoffland, E., Wei, C. and Wissuwa, M. 2006. Organic anion exudation by lowland rice (Oryza sativa L.) at zinc and phosphorus deficiency. Plant Soil, 283:155-162.

Hajiboland, R., Yang, X.E., Romheld, V. and Neumann, G. 2005. Effect of bicarbonate on elongation and distribution of organic acids in root and root zone of $\mathrm{Zn}$ efficient and $\mathrm{Zn}$ inefficient rice (Oryza sativa L.) genotypes. Environmental and Experimental Botany, 54:163-173.

Hacisalihoglu, G., Hart, J.J., Wang, Y.H., Cakmak, I. and Kochian, L.V. 2003. Zinc efficiency is correlated with enhanced expression and activity of zinc-requiring enzymes in wheat. Plant Physiol., 131(2):595-602.

Kirk, G.J.D. and Bajita, J. B. 1995. Rootinduced iron oxidation, $\mathrm{pH}$ changes and zinc solubilization in the rhizosphere of lowland rice. New Phytol., 131:129137.

Marschner, H. 1995. Mineral Nutrition of Higher Plants. 2nd edn. Academic Press, London. pp. 889.

Pinton, R., Cakmak, I., Marschner, H. 1993. Effects of zinc deficiency on protonuxes in plasma membrane-enriched vesicles isolated from bean roots. Journal of Experimental Botany 44: 623-630.

Rengel, Z. 1999. Zinc deficiency in wheat genotypes grown in conventional and chelator-buffered nutrient solutions. Plant Science, 143:221-230

Rengel, Z., Romheld, V. and Marschner, H. 1998. Uptake of zinc and iron by wheat genotypes differing in zinc efficiency, $J$. Plant Physiol, 152: 433-438.

\section{How to cite this article:}

Deepa Rawat, Santosh Chandra Bhatt, P.C. Srivastava and Pachauri, S.P. 2019. Effect of Zn Application on Rhizosphere Acidification in Rice and Wheat Varieties of Varying $\mathrm{Zn}$ Sensitivity. Int.J.Curr.Microbiol.App.Sci. 8(06): 1033-1038.

doi: https://doi.org/10.20546/ijcmas.2019.806.126 